This is a post-print (author's final draft) of an article in the journal Contemporary Music Review (2006), 25, 1/2, pp. 59-68. [Original page numbers between square brackets]. Details of the definitive version are available at http://www.tandfonline.com/doi/full/10.1080/07494460600647451

\title{
Music Cognition and the Bodily approach: Musical Instruments as Tools for Musical Semantics
}

\section{Mark Reybrouck}

\begin{abstract}
This article is about music cognition and the role the body plays in its acquisition. It argues for a processual approach to dealing with music rather than conceiving of music as an artefact. Leaning heavily on the older philosophical writings of Dewey, it tries to provide an operational approach to the musical experience, with a special focus on the sensory-motor interactions of the music user with the sonic world. As such, it is possible to conceive of the music user as an adaptive device, with natural perceptual and effector tools that can be modified at will. It is argued, further, that musical instruments can be considered as artificial extensions of these natural tools, allowing us to conceive of them in epistemological terms as tools for music knowledge acquisition.
\end{abstract}

Keywords: Music Cognition; Interaction; Adaptive Device; Tool Using; Music Instruments; Semantics

\section{Introduction}


[59] This article is about music cognition and the role the body plays in the acquisition of music knowledge in general (for an exhaustive overview, see Reybrouck, 2005b). Music, actually, is not to be dealt with merely in objectivistic terms - as something 'out there' that can be reified or objectified. Dealing with music, rather, is a process that calls forth music users who are coping with the sounds. This 'coping behaviour' involves several kinds of interactions that can be internalised - as in listening and imagery - as well as manifest. The latter are obvious in instrumental playing, which stresses the effector side of dealing with the music. Yet even listening and imagery can be conceived of in action terms, be it at a level that is not goal-directed and manifest. There is, in fact, a strong connection between action, imagery and perception in the sense that these processes activate some of the same structures in the brain.

[60] The neurobiological grounding for these claims is very intriguing as it provides empirical support for hypotheses that were rather intuitive up to now (Peretz \& Zatorre, 2003; Zatorre \& Peretz, 2001). There is no space to go into detail here, but some general findings should be mentioned at least: music users are biological organisms that have a body equipped with the necessary tools for action, perception and processing at the level of mental operations. These tools can be natural, but they can be extended by using artificial tools as well. A major claim of this article will be that music users use musical instruments as tools for coping with the sound not only at the effector level of playing music, but also at the perceptual level of dealing with the sound. As such, it is possible to conceive of musical instruments in epistemological terms as tools for music knowledge acquisition.

Setting the Problem: The Inside/Outside and Subjective/Objective Dichotomies 
Musicology has a long tradition of objectivation of music as an artefact - the musical work as 'artwork' - relying heavily on score analysis and symbolic representations of the music. Dealing with music, however, involves a subjective involvement of the music user as well. It is up to the listener to, for example, make sense of the sounding flux and it is up to the performer to provide a convincing interpretation of the work. How does one deal with this subjective/objective asymmetry? In what follows, I will try to deliver an operational description of the subjective involvement with music, focusing mainly on some major topics and quoting rather extensively from some seminal writings. The topics are: the subjective/objective distinction, the inside/outside dichotomy, the role of focal adjustment, and the role of transactions at the boundaries.

\section{The Subjective/Objective Distinction}

The subjective/objective distinction has been treated extensively in the philosophical writings of Dewey (1958 [1934]) and James (1976 [1912]) who conceived of it as an artificial distinction - of a practical and functional orderrather than an ontological one. To the extent that a 'perceiving subject' can be distinguished from a 'perceived object', it is possible to deal with a perceptual experience in subjective terms as 'representing' and in objective terms as 'being represented'. According to James, there simply is no self-splitting of the perceiver into consciousness and what the consciousness is of: ' $[\mathrm{N}] \mathrm{o}$ dualism of being represented and representing resides in the experience per se. ... It is only virtually or potentially either object or subject as yet. For the time being, it is plain, unqualified actuality, or existence' (McDermott, 1968, p. 177). Subjectivity and objectivity are functional attributes solely, realised 
only when the experience is 'taken' twice, considered along with its two differing contexts respectively. This is true, especially for dealing with music, where the distinction between subject and object is rather faint.

\section{[61] The Inside/Outside Dichotomy}

A critical question here is the topological position of the musical experience. Music, in fact, can be considered as something that is happening inside as well as outside the human body - an internal or external phenomenon. As such, the distinction is related to the objective-exosomatic and subjective-endosomatic dichotomy: regarding the body as a privileged context of external reference, it is possible to divide the total universe of our discourse into 'subjective' and 'objective' realms (Lidov, 1987). It reminds us of the basic distinction between the 'egocentric' and 'allocentric world', and the related distinction between 'endosomatic' and 'exosomatic space'. To quote Lidov (1987, p. 75):

The endosomatic world is one we feel; the exosomatic world, one we see. The exosomatic realm, preeminently visual, is stabilized and articulated by the physiology of Gestalt perception. Its objects commute without apparent distortion. ... The endosomatic realm is largely unarticulated. ... [I]t has its distinctive entities just as the other space has its fogs and clouds. ... But as a general rule the conditions of the body fade into each other and effect each other, and there is only a little room to maneuver when it comes to reordering them. The endosomatic space is chiefly a realm of flux and influence. Its chief contents are hanging states rather than fixed objects.

\section{The Role of Focal Adjustment}

The problem of subjectivity is also related to the focal adjustment of the perceiver who chooses appropriate settings for structuring the perceptual field in 
a specific manner. What is meant is the construal of a specific relationship between perceiver and perceived thing. As Langacker (1987, p. 129) puts it:

[T]here is an optimal viewing arrangement in which the object being observed stands sharply differentiated from its surroundings, and in a region of perceptual acuity. In general this region is close to the observer, but does not include the observer himself. This is the objective scene for the locus of viewing. In this the asymmetry in the roles of observer and object are maximized: the role of the observer is said to be maximally subjective, that of the observed object maximally objective.

This is obvious for the visual field of perception. The question, however, is how to translate this to the realm of music. Much depends here on the kind of interactions with the sounds: playing an instrument, for example, relies on eyes and ears as well as on information from the hands and limbs, but bypassing one of these senses enables the music user to shift attentional focus from a rather outwardly oriented direction to a kind of internalised processing that is closer to the endosomatic/subjective realm of cognition and the related 'stratification' of his/her inner space.

\section{[62] The Role of Transactions at the Boundaries}

This brings us to the mutually related concepts of interactions and transactions between the objective and subjective conditions of experience. Interactions, as they are commonly defined, are merely mechanical. They involve unchanging entities that become intertwined, but retain their separate identities. The concept of transaction, on the contrary, implies a more fluid, interpenetrating relationship between objective conditions and subjective experience: once they become related, both of them are essentially changed (Kolb, 1984, p. 36). 


\title{
Dealing with Music: Towards an Experiential Approach
}

Starting from the subjective/objective dichotomy, it is possible to conceive of music as something that is located inside or outside the body. The boundary, however, is not to be considered as a static separating wall as musical behaviour is outwardly (e.g., performing) as well as inwardly (e.g., listening, imaging) oriented. A more fruitful approach is to conceive of it as a dynamic interface that allows interactions between 'incoming and outgoing energy', to borrow Dewey's description of having an experience:

\begin{abstract}
[A]rt, in its form, unites the very same relation of doing and undergoing, outgoing and incoming energy, that makes an experience to be an experience. . . Man whittles, carves, sings, dances, gestures, molds, draws and paints. The doing or making is artistic when the perceived result is of such a nature that its qualities as perceived have controlled the question of production. The act of producing that is directed by intent to produce something that is enjoyed in the immediate experience of perceiving has qualities that a spontaneous or uncontrolled activity does not have. The artist embodies in himself the attitude of the perceiver while he works. (Dewey, 1958 [1934], p. 48)
\end{abstract}

In an attempt to elaborate on this description, I will focus on some main topics in order to provide an operational approach to these 'experiential' claims. I see essentially three of them: the concept of dealing with the music, the role of sensorymotor integration, and the concept of coping with the sound. Central in the 'experiential' approach is the concept of dealing with music. It can be defined generically to encompass traditional musical behaviours - such as listening, performing, improvising and composing — as well as more general 'perceptual' and 'behavioural' categories. These broader categories encompass activities such as exploring, selecting and focusing of attention-on the 
perceptual side - and actions, interactions and transactions with the (sonic) world — on the behavioural side. Common to these behaviours is the reciprocity of 'doing and undergoing', or put in operational terms: the sensory-motor integration.

The concept of sensory-motor integration is very fruitful: it links the perceptual (sensorium) and effector world (motorium) by carrying out mappings and coordinations between sensory input and motor output (the term 'motor' refers to the broad domain of all that is related to movement). As such, it is related to the [63] 'cybernetic concept' of a control system that embraces the four major elements ofadaptive control: input, output, central processing and feedback (see Figure 1). The concept is not common knowledge among musicians and musicologists, yet its musical applications are obvious (Reybrouck, 2006). A musician who plays the violin, for instance, is performing motor acts that are fed back through the senses to the central processing mechanism (the musician's brain). This is conservative behaviour: the musician keeps step with the unfolding of the perceptual (sounding) flux in an attempt to achieve or to maintain a state of equilibrium by 'measuring' and 'controlling' all possible perturbations. The role of sensory-motor integration is obvious here: it allows us to think of the music user in functional terms as a controller or a measuring device which is most typically exemplified in music performance, if we conceive of this as 'a skilled activity that requires the simultaneous integration of multimodal sensory and motor information with multimodal sensory feedback mechanisms to monitor performance' (Gaser \& Schlaug, 2003, p. 9240). Dealing with music, in this view, is a continuous process of coping with the sounds (Reybrouck, 2001). This term, which is an 'ecological' concept, is used mostly with regard to the physical environment of an animal - the prey to catch, the predators to avoid - but it can be extended to be used also with regard to 'musical' or 'sonic environments' of music users in general. As such, it is 
possible to conceive of music knowledge construction as the result of interactions with the sounding environment. It allows music users to arbitrarily choose what kinds of 'distinctions' are to be made (the perceptual categories), what kinds of 'actions' are to be done on the environment (the action categories) and what kinds of 'coordinative mappings' between perception and action must be carried out (Reybrouck, 2005a). Music users, in this view, can be considered as adaptive systems that continually modify their internal structure in response to experience. The whole process is diagrammed schematically in Figure 2 as a 'perception-cognition-action loop' (Cariani, 2001, 2003). Basic in this approach is the 'organism-environment interaction' with an epistemic cut between the music user (the organism) and the music (the environment). The interactions, further, can be carriedout at the perceptual and the effector levels with the mind of the music user functioning as the central processing mechanism doing the coordination and cognising.

\section{Music Users as Adaptive Devices: The Role of Sense-making and Tool Using}

Dealing with music is a process of sense-making and adaptive control if we are ready to conceive of music users as adaptive devices who can learn to make new distinctions

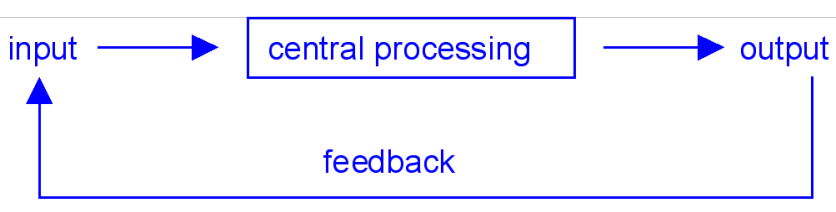

Figure 1. The major moments of a control system. 


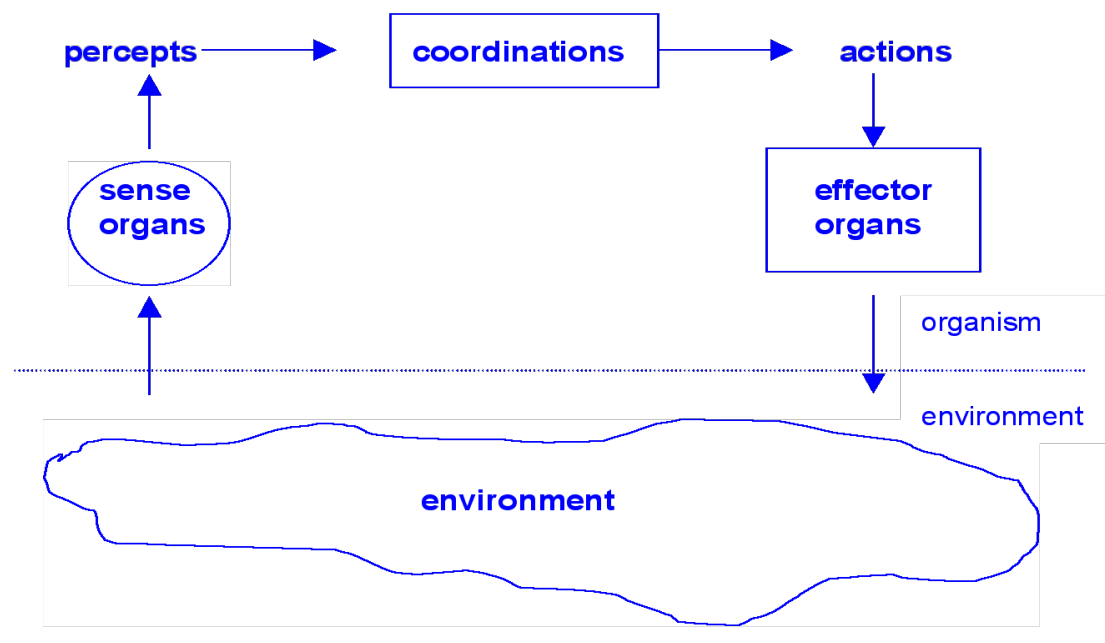

Figure 2. Diagram of a perception-cognition-action loop (after Cariani, 1989).

[64] (expanding their set of observables), to perform new actions on the sounding environment and to carry out new mental operations on the observables (Reybrouck 2005a, 2006). This holds true for a composer who is trying out new elements and rules of combinations through exploratory listening and performing, but also for a listener or performer. What matters is the interaction with the sounds through sound-producing actions and mental operations performed on actual sounding material or on mental replicas of the sounds. These interactions have a crucial role: they provide the needed sensory input for the construction of music knowledge, especially with respect to musical source material and the causal relations between the sound producing actions and their sounding results.

Adaptive devices are able to change their semantic relations to the world: the way they try to construct meaning (semantics is the part of semiotics concerned with meaning) out of the perceptual (sounding) flux is dependent on the adaptations at each level of their functioning — namely the sensing, the effector 
and the coordinating function. Yet devices can even change their structure by adding extensions such as sensing or effector tools. As such, there can be adaptation both at the 'functional' and the 'structural' level.

As to the sensing function, it is possible to modify or augment the sensors, allowing the device to choose its own perceptual categories and control the types of empirical information it can access. Several strategies are possible here (Cariani, 1991, 1998), but the basic mechanisms are reducible to two: to alter the existing sensing functions or to add new ones. Accordingly, there are four possibilities: prosthesis or adaptive fabrication of new front-ends for existing sensors, active sensing or using motor actions to alter what is sensed through interaction (poking, pushing, bending), sensory evolution or adaptive construction of entirely new

[65] sensors, and internalised sensing by creating internal, analog representations of the world out of which internal sensors extract newly relevant properties (Cariani, 1998, p. 718).

As to the effector function, there is the possibility of 'active measurement' as a process of acting on the world and sensing how this world behaves as a result of actions one performs on it. This is 'active sensing', which changes our sensing function without altering the sensor structures, requiring only additional coordinative and motor resources to be used. The coordinating function is related to the central processing of the control system. It enables the construction of better 'cognitive tools' for dealing with the sounding music and allows the music user to handle information processing in terms of a "transfer function' from the sensory to the motor field, leaning heavily on innate and wired-in mechanisms of information processing. 
Feedback, finally, has a special role in knowledge construction: it brings together the sensing and effector function of devices by feeding back the outcome of an action to its initiator. Applied to music, this is mostly related to the continuous control of sound characteristics (pitch, intensity, timbre, articulation, etc.) during the generation by means of continuous modifications of the physical parameters of the sound. This is obvious in playing traditional wind and bow instruments and in singing, all of which allow the performer to sculpt the sound by continuously adjusting the sounding results.

The musical analogies of these claims are obvious. Instruments, in particular, are extensions of our natural tools, especially for performing (action). Instruments, however, are able also to resonate to other sounds that are tuned in specific frequency ratios to the resonating frequency and provide the minimal sound level that is needed for actually perceiving and evaluating the produced sounds. Instruments, in this view, do not merely concern the output-oriented musical behaviours (playing), but they can be considered perceptual tools as well. The situation, however, is getting still more complicated as soon as the human ear and motor interfaces are replaced by robots and computers. Computers are able to make distinctions that go beyond the constraints of perception, and the same holds true for their performance abilities. We now have at our disposal tools for better listening, for computer-aided composition and for performing.

\section{Musical Instruments as Tools for Musical Semantics}

To conceive of music users as 'adaptive devices' is a challenging approach. The concept has descriptive and explanatory power and goes beyond the conception of a human being as a camera and of cognition as a kind of photographic image of the outside world. It argues, on the contrary, for a dynamic approach to 
cognition that replaces the robot concept by that of a 'system' emphasising immanent activity rather than outer-directed reactivity and allowing the device to make use of several extensions at the interfaces. What I mean, especially, is the role of tools at the perceptual and effector interface, both natural and artificial ones. Adaptation, on this view, is possible

[66] at several levels of functioning. According to Cariani (1991, 2001, 2003) there are three major possibilities: to amplify the possibilities of participatory observation by expanding the perceptual and behavioural repertoire of the system; to adaptively construct sensory and effector tools; and to change the cognitive tools as well.

The role of musical instruments is obvious here: instruments are extensions of the human body, both at the perceptual and effector sides, which can be used as tools for better interaction with the sounding environment. I see four possibilities for elaborating on this claim: instruments for better sensing or perceiving, instruments for producing sound, instruments for input/output mappings, and instruments as tools for changing semantic relations with the sounding world. As to the first, there is a critical distinction between dealing with music at the level of imagery as against theactual experience of music in real time. Imagery, as a rule, is not constrained. Perception is constrained: there are limitations regarding what listeners can actually hear and meaningfully process. As such, there can be a mismatch between what composers believe to be meaningful and what listeners actually can perceive and process. These constraints, however, can be overcome if artificial instruments are substituted for our natural perceptual tools. This has been the case with the new technologies that provide tools for better listening such as spectrographic or microscopic listening (Reybrouck, 2004), navigation tools for sonic browsing 
(Aigrain, 1999), and musical signal analysis and processing. These new developments are not yet fully implemented in current musicological research, but the field is very promising in bringing together technical know-how from acoustics, sound engineering and cognitive musicology.

Instruments are tools for the production of sound. Yet there are limitations as to what a human performer can actually accomplish with his or her instrument (speed of playing, loudness of sound, number of divisions in the pitch continuum, etc.). These constraints, however, can be easily overcome if the music user relies on technological means instead of on human craftsmanship. There is, nowadays, a new science of sound that embraces the technology of both production and control of sound, and the explosion of technological means for digital audio-processing and the use of new equipment in computer music all point in this direction (Tarabella \& Bertini, 2002).

Music theory, as we now conceive of it, relies on sensors instead of receptors, substituting tools for organs and introducing several kinds of machinery that can generate, transform and control many kinds of movements and sound production (Dufourt, 2001). Musical instruments, in this view, can be transformed into automata that receive, transduce and analyse the information. As such, it is possible to conceive of the construction of virtual instruments with different kinds of sensors and effectors, the introduction of robotics in the construction of musical instruments, and the usage of computers as controllers instead of the traditional performer.

Traditional musical instruments, according to Tarabella and Bertini (2002), are:

[C]ompact tools which gather together the aspects which are necessary for stating and determining timbre and for controlling pitch and nuances of sound. In these traditional instruments there is a one-to-one mapping rule between the movements [67] of the performer and the sounding result. There is a feedback loop which enables continuous control of sound 
characteristics (pitch, intensity, timbre, articulation, etc.) by means of continuous modifications of the physical synthesis parameters.

This 'mapping', however, can be problematic at times. This is the case, for example, with acousmatic listening (Chion, 1983; Schaeffer, 1966) where the listener is encouraged to focus on the sonic properties of the sounds without any reference to their visible sources. This is a kind of 'reduced listening' where acousmatic sounds are heard through loudspeakers without any clue as to their causes. These acousmatic sounds - so typical of 'acousmatic arts' and 'musique concre'te'-go beyond an 'explanatory' way of listening in concealing any straight connection between the sound-as-heard and any sound-producing action. This causal relationship is abandoned even more dramatically in computer music performance when original controllers based on different kinds of sensors (pressure, acceleration, heat, infraredbeams, ultrasound, etc.) or gesture recognition systems are used by the performer. Here the mapping between gesture and sound is really problematic.

The mapping problem is a semiotic problem. It challenges the natural way of making sense out of the sounding music in obscuring the causal relation between sound-producing actions and their sounding results. To the extent that this is problematic, it can be considered a challenge as well. Music users, then, can extend their natural tools for sense-making by carrying out interactions with the sounds, both at a physical level—with one-to-one mappings between the sound-producing actions and the resulting sounds - as well as at a level that conceals this causal relationship by interposing intermediate modifications and manipulations of thesound. As such, the music user can change his or her semantic relationships with the sounding world by using either traditional instruments or more sophisticated technological extensions of sound-producing devices. It allows us to conceive of the music user as an 'adaptive device' 
capable of changing its sensors, effectors and the mental processing of the sounds (Reybrouck, 2006).

\section{Conclusion and Perspectives}

In this article, I have argued for a processual approach to dealing with music. It is an approach that stresses the bodily activities - if only at a subliminal levelthat are involved in the production and perception of the sounds as well as the role of carrying out interactions with the sounds. Starting from the subjective/outside distinction and its topological inside/outside analogies, I have elaborated on the possible interactions that can be located at each level of the cybernetic control system. The role of perceptual and effector interfaces is especially important here, both for natural and artificial tools. To the extent that the music user can rely on them for modifying the interactions with the sonic world, it is possible to conceive of him or her as an adaptive device that can change its semantic relations with the world. The role of music instruments, as an example of artificial tools, is extremely important here. I conceive of them not only in terms of effector tools for producing [68] sounds, but as tools for sense-making as well. As such, they can be considered as tools for musical semantics.

\section{References}

Aigrain, Ph. (1999). New Applications of Content Processing of Music. Journal of New Music Research, 28(4), 271-280. 
Cariani, P. (1989). On the design of devices with emergent semantic functions. Unpublished doctoral dissertation. New York: State University of New York.

Cariani, P. (1991). Some epistemological implications of devices which construct their own sensors and effectors. In F.Varela, F. \& P.Bourgine (Eds.), Towards a Practice of Autonomous Systems. Proceedings of the First European Workshop on Artificial Life (pp. 484-493). Cambridge MA: MIT Press.

Cariani, P. (1998b). Life's journey through the semiosphere. Semiotica, 120(3/4), 243-257.

Cariani, P. (2001). Symbols and dynamics in the brain. Biosystems, 60(1-3), 5983. Special issue on "Physics and evolution of symbols and codes". Cariani, P. (2003). Cybernetic systems and the semiotics of translation. In S.Petrilli (Ed.), Translation Translation (pp. 349 - 367). Amsterdam: Rodopi.

Chion, M. (1983). Guide des objets sonores. Paris: Editions Buchet/Chastel. Dewey, J. (1934/1958). Art as Experience. New York: Capricorn Books. Dufourt, H. (2001). Les principes de la musique. In: Deliège \& M.Paddison (Eds.), Musique contemporaine. Perspectives théoriques et philosophiques (pp. 13-83). Sprimont: Mardaga.

Gaser, Ch. \& G.Schlaug (2003). Brain Structures Differ between Musicians and Non-Musicians. The Journal of Neuroscience, 23 (27), 9240-9245. James, W. (1912/1976). Essays in Radical Empiricism. Cambridge (Ma) London: Harvard University Press.

Kolb, D. (1984). Experiential learning. Experience as The Source of Learning and Development. New Jersey: Prentice-Hall.

Langacker, R. (1987). Foundations of cognitive grammar, Vol. 1. Stanford CA: Stanford University Press. 
Lewin, K. (1936). Principles of Topological Psychology. New York - London: McGraw-Hill Book Company.

Lidov, D. (1987). Mind and body in music. Semiotica, 66(1/3), 69-97.

McDermott, J. (Editor) (1968). The Writings of William James. A

Comprehensive Edition. New York: Random House.

Peretz, I. \& R.Zatorre (Eds.). 2003). The Cognitive Neuroscience of Music.

Oxford - New York: Oxford University Press.

Reybrouck, M. (2001). Biological roots of musical epistemology: Functional

Cycles, Umwelt, and enactive listening. Semiotica, 134(1-4), 599-63.

Reybrouck, M. (2004). Music Cognition, Semiotics and the Experience of Time.

Ontosemantical and Epistemological Claims. Journal of New Music Research, 33(4), 411-428.

Reybrouck, M. (2005a). A Biosemiotic and Ecological Approach to Music

Cognition: Event Perception between Auditory Listening and Cognitive

Economy. Axiomathes. An International Journal in Ontology and Cognitive Systems, 15(2), 229-266.

Reybrouck, M. (2005b). Body, mind and music: musical semantics between experiential cognition and cognitive economy. Trans. Transcultural Music Review, 9. Retrieved from http://www.sibetrans.com/trans/

Reybrouck, M. (2005c). Musical Creativity between Symbolic Modelling and Perceptual Constraints: the Role of Adaptive Behaviour and Epistemic Autonomy. In I.Deliège \& G.Wiggins (Eds.), Musical Creativity: Current Research in Theory and Practice. Psychology Press: Oxford (forthcoming). Reynolds, R. (2002). Compostional strategies in the angel of death for piano, chamber orchestra and computer processed sound. In C.Stevens, D.Burnham, G.McPherson, E.Schubert, J.Renwick (Eds.), Proceedings of the 7th International Conference on Music Perception and Cognition, Sydney 2002 ( pp. 15-18). Adelaide: Causal Productions. 
Roads, C., S.Pope, A.Piccialli \& G. de Poli (Editors.) (1997). Musical Signal Processing. Lisse - Abingdon - Exton -Tokyo: Swets \& Zeitlinger.

Schaeffer, P. (1966). Traité des objets musicaux. Paris: Editions du Seuil. Tarabella, L. \& G.Bertini (2002). The mapping Paradigm in Gesture Controlled Live Computer Music. In M. Olivetti Belardinelli et al. (Eds.) (2002), Proceedings of the 2nd International Conference "Understanding and Creating Music", 21 - 25 November, Caserta.

Zatorre, R. \& I.Peretz (Editors.) (2001). The Biological Foundations of Music.

New York: Annals of the New York Academy of Sciences, Vol. 930, 281299.

\section{Biographical note}

Mark Reybrouck ( $\left.{ }^{\circ} 1952\right)$ studied physical education, physical therapy and musicology. He has been working as a music educator for years and is currently professor of music at the University of Leuven (section of musicology) where he is course holder of the teaching methodology of music. His interests concern the interdisciplinary approach to musicology in general with a special interest in musical semiotics and the biological roots of musical epistemology. He published a number of articles about musical semantics and the biosemotic approach to music and is currently involved in empirical research onto the listening behaviour and listening strategies of children without formal music training. 